\title{
ORIGINAL ARTICLE Inhibition of nitric oxide production in lipopolysaccharide-activated RAW 264.7 macrophages by Jeju plant extracts
}

\author{
Eun-Jin YANG 1,2, Eun-Young YIM 1,2, Gwanpil SONG 1,2, Gi-Ok KIM 2, Chang-Gu HYUN 1,2 \\ 1 Jeju Biodiversity Research Institute (JBRI), Seogwipo-si, Jeju 699-943, Korea \\ 2 Jeju Hi-Tech Industry Development Institute (HiDI), Ara-1-dong, Jeju 690-121, Korea
}

ITX020409A03 • Received: 10 September 2009 • Revised: 21 November 2009 • Accepted: 28 November 2009

\begin{abstract}
Nitric oxide (NO) produced in large amounts by inducible nitric oxide synthase (iNOS) is known to be responsible for the vasodilation and hypotension observed during septic shock and inflammation. Thus, inhibitors of iNOS may be useful candidates for the treatment of inflammatory diseases accompanied by the overproduction of NO. In this study, we prepared alcoholic extracts of Jeju plants and screened them for their inhibitory activity against NO production in lipopolysaccharide (LPS)-activated macrophages. Among the 260 kinds of plant extract tested, 122 extracts showed potent inhibitory activity towards NO production by more than $25 \%$ at a concentration of $100 \mu \mathrm{g} / \mathrm{mL}$. Plants such as Malus sieboldii, Vaccinium oldhamii, Corylus hallaisanensis, Carpinus laxiflora, Styrax obassia, and Securinega suffruticosa showed the most potent inhibition (above 70\%) at a concentration of $100 \mu \mathrm{g} / \mathrm{mL}$. The cytotoxic effects of the plant extracts were determined by colorimetric MTT assays and most plant extracts exhibited only moderate cytotoxicity at $100 \mu \mathrm{g} / \mathrm{mL}$. Therefore, these plants should be considered promising candidates for the further purification of bioactive compounds and would be useful for the treatment of inflammatory diseases accompanying overproduction of NO.
\end{abstract}

KEY WORDS: cytotoxicity; inflammation; nitric oxide; plant extract

\section{Introduction}

Nitric oxide (NO), which is synthesised by nitric oxide synthase (NOS) from L-arginine using NADPH and molecular oxygen, is a short-lived free radical and an intercellular messenger produced by a variety of mammalian cells, which include macrophages, neutrophils, platelets, fibroblasts, endothelium, neuronal, and smooth muscle cells. NO mediates a variety of biological actions ranging from vasodilatation, neurotransmission, inhibition of platelet adherence and aggregation, as well as the macrophage- and neutrophil-mediated killing of pathogens (Moncada et al., 1991, MacMicking et al., 1997; Oh et al., 2008). Chronic inflammation and infections lead to the up-regulation of a series of enzymes and signaling proteins in affected tissues and cells. The inducible forms of NOS are the most important

Correspondence address:

\section{Chang-Gu Hyun, PhD.}

Jeju Biodiversity Research Institute (JBRI),

Jeju High-Tech Development Institute (HiDI), Jeju 699-943, Korea

TEL.: +82-64-720-2811 • E-MAlL: cghyun@jejuhidi.or.kr pro-inflammatory enzymes responsible for increasing the levels of NO. Three isoforms of NOS have been identified and are classified into the following two major categories: constitutive and inducible. Expression of iNOS catalyses the formation of large amounts of NO, which plays a key role in the pathogenesis of a variety of inflammatory diseases. Therefore, the level of NO induced by iNOS may reflect the degree of inflammation and provides an indicator to assess inflammatory processes. Recently, several iNOS inhibitors have been reported as being isolated from plants such as 4-O-methylhonokiol (Oh et al., 2009), fraxinellone (Kim et al., 2009), 6-gingerol (Lee et al., 2009), tanshinone IIA (Fan et al., 2009), and arctigenin (Zhao et al., 2009). In addition, most of the inhibitory activity of these compounds towards NO production has been demonstrated to be through the inhibition of iNOS expression.

Plants have formed the basis of sophisticated traditional medicine systems that have been in existence for thousands of years across the globe. These plant based medicinal systems continue to play an essential role in health care today, and it has been estimated by the World Health Organization that approximately $80 \%$ of the world's inhabitants rely mainly on traditional medicines for primary health care (Cragg and Newman, 2008; Hsieh et al., 2008). Owing to its 
unique ecosystem, Jeju Island is famous for the richness and diversity of its flora with over 7800 species classified to date. Over the past few years, we have systematically evaluated and characterised selected plant species for their putative bioactivities or potential medicinal applications. In order to find new iNOS inhibitors from endemic Jeju plants, we have established a screen for the inhibitory activity towards NO production by measuring its production in LPS-stimulated RAW 264.7 cells.

\section{Materials and methods}

\section{Plant materials and solvent extraction}

The plants were collected from Jeju Island, Korea from 2006 to 2008. Voucher specimens were deposited at the herbarium of Jeju Biodiversity Research Institute. Verification of vouchers or living plants was performed by Dr. Gwanpil Song. Plant materials were air-dried, ground and extracted three times with $80 \%$ ethanol at room temperature. After the sample was filtered through two layers of cheesecloth, the filtered cakes were extracted and filtered three more times to increase the extraction yield. The filtrates were concentrated under reduced pressure, freeze-dried, and stored in a closed container until testing.

\section{Cell culture}

Murine macrophage RAW 264.7 cells were purchased from the Korean Cell Line Bank (Seoul, Korea). They were cultured in Dulbecco's modified Eagle's medium (DMEM) containing $2 \mathrm{mM}$ glutamine, $10 \mathrm{mM}$ 4-[2-hydroxyethyl]1-piperazineethanesulfonic acid (HEPES), penicillin (100 units $/ \mathrm{mL})$, streptomycin $(100 \mu \mathrm{g} / \mathrm{mL})$ and $10 \%$ foetal bovine serum. Cells were cultured at $37^{\circ} \mathrm{C}$ in a humidified incubator with an atmosphere of $5 \% \mathrm{CO}_{2}$.

\section{MTT assay for cell viability}

3-(4,5-dimethylthiazol-2-yl)-2,5-diphenyltetrazolium bromide (MTT) is a pale yellow substrate that is reduced by living cells to yield a dark blue formazan product. This process requires active mitochondria, and only freshly dead cells do not reduce significant amounts of MTT. RAW 264.7 cells were cultured in 96-well plates for $18 \mathrm{hr}$, followed by treatment with LPS $(1 \mu \mathrm{g} / \mathrm{mL})$ in the presence of plant extracts at concentrations of $100 \mu \mathrm{g} / \mathrm{mL}$. After a $24 \mathrm{hr}$ incubation, MTT was added to the medium for $4 \mathrm{hr}$. Finally, the supernatant was removed and the formazan crystals were dissolved in dimethyl sulfoxide (DMSO). Absorbance was measured at $540 \mathrm{~nm}$. The percentage of dead cells was determined relative to the control group.

\section{Nitric oxide assay}

The nitric oxide assay was performed as described previously with slight modification (Yoon et al., 2009). After pre-incubation of RAW 264.7 cells $\left(1.5 \times 10^{5}\right.$ cells $\left./ \mathrm{mL}\right)$ with LPS $(1 \mu \mathrm{g} / \mathrm{mL})$ for $24 \mathrm{~h}$, the quantity of nitrite in the culture medium was measured as an indicator of $\mathrm{NO}$ production. Amounts of nitrite, a stable metabolite of NO, were measured using Griess reagent (1\% sulfanilamide and
$0.1 \%$ naphthylethylenediamine dihydrochloride in $2.5 \%$ phosphoric acid). Briefly, $100 \mu \mathrm{L}$ of cell culture medium was mixed with $100 \mu \mathrm{L}$ of Griess reagent. Subsequently, the mixture was incubated at room temperature for $10 \mathrm{~min}$ and the absorbance at $540 \mathrm{~nm}$ was measured in a microplate reader. Fresh culture medium was used as a blank in every experiment. The quantity of nitrite was determined from a sodium nitrite standard curve.

\section{Results and discussion}

In murine macrophage RAW 264.7 cells, LPS stimulation alone has been demonstrated to induce iNOS transcription and its protein synthesis, with a corresponding increase in NO production. Furthermore, LPS stimulation has also been shown to induce IкB proteolysis and NF- $\mathrm{KB}$ nuclear translocation (Xie et al., 1994; Henkel et al., 1993). Therefore, this cell system is an excellent model for drug screening and the subsequent evaluation of potential inhibitors against iNOS and NO production. In our search for natural products with anti-inflammatory activity, we prepared $80 \%$ ethanol crude extracts of 260 native plants from Jeju Island, Korea. All the plant samples were dissolved in $80 \%$ ethanol and diluted with sterile water to normalise the concentration of the test sample. The Griess reaction, a spectrophotometric determination for nitrite, was carried out to quantify the nitrite levels in the conditioned medium of RAW 264.7 cells treated with LPS. The final concentration of ethanol in the culture media was $0.1 \%$ and this concentration of ethanol did not show any effect on the assay systems. Table 1 shows the inhibitory activity by plant extracts towards NO production by LPS-activated macrophages. Of the 260 kinds of extracts, 122 extracts showed greater than $25 \%$ inhibition of NO production at the concentration of $100 \mu \mathrm{g} / \mathrm{mL}$ in the culture media. Among these 122 extracts, Acer pictum, Viburnum dilatatum, Melia azedarach, Lonicera japonica, Osmunda japonica, Alnus firma, Lindera erythrocarpa, Platycarya strobilacea, Rhododendron werrichii, Weigela subsessilis (, Salix koreensis, Magnolia kobus, Corylus sieboldiana, Cornus walteri, Ulmus parvifolia, Morus bombycis, Aria alnifolia, Neoshirakia japonica, Actinodaphne lancifolia, Triadica sebifera, Elaeagnus umbellata, Oenothera glazioviana, Ficus erecta var. sieboldii, Rubus buergeri, Orixa japonica, and Cnidium japonicum showed the most potent inhibition (greater than $70 \%$ inhibition) at the concentration of $100 \mu \mathrm{g} /$ $\mathrm{mL}$. The numbers of viable activated macrophages were not significantly altered by the plant extracts as determined by MTT assays, thereby indicating that the inhibition of NO synthesis by the plant extracts was not simply due to cytotoxic effects. Although some plant extracts such as Idesia polycarpa, Artemisia scoparia, and Elsholtzia splendens also exhibited potent inhibition (above 70\%) towards NO synthesis at $100 \mu \mathrm{g} / \mathrm{mL}$, there were some cytotoxic effects.

To conclude, these data suggest that extracts from the plant species examined in this study deserve further investigation in order to isolate the bioactive secondary metabolites with anti-inflammatory properties. Currently, experiments are in progress to analyse the active fractions from the 
Table 1. Nitric oxide inhibition and cytotoxicity of Jeju plant extracts.

$\begin{array}{ll}\text { Scientific names } & \text { Parts }\end{array}$

Carpinus laxiflora (Siebold \& Zucc.) Blume

Elsholtzia splendens Nakai ex F. Maek.

Artemisia scoparia Waldst. \& Kit.

Securinega suffruticosa (Pall.) Rehder

Styrax obassia Siebold \& Zucc.

Malus sieboldii (Regel) Rehder in Sarg.

Idesia polycarpa Maxim.

Corylus hallaisanensis Nakai

Vaccinium oldhamii Miq.

Elaeagnus umbellata Thunb. in Murray

Carpinus turczaninowii Hance

Corylus sieboldiana Blume

Cudrania tricuspidata (Carriere) Bureau ex Lavallee

Triadica sebifera (L.) Small

Ternstroemia gymnanthera (Wight \& Arn.) Sprague

Neoshirakia japonica (Siebold \& Zucc.) Esser

Melia azedarach L.

Toxicodendron succedaneum (L.) Kuntze

Fraxinus mandshurica Rupr.

Euscaphis japonica (Thunb.) Kanitz

Sorbus commixta Hedl.

Lonicera japonica Thunb. in Murray

Malus sieboldii (Regel) Rehder in Sarg.

Ligustrum obtusifolium Siebold \& Zucc.

Osmunda japonica Thunb.

Aria alnifolia (Siebold \& Zucc.) Decne.

Orixa japonica Thunb.

Vaccinium bracteatum Thunb. in Murray

Acer pictum Thunb. in Murray var. mono (Maxim.) Maxim. ex Franch.

Salix koreensis Andersson in DC.

Sorbus alnifolia for. hirtella (Nakai) W. T. Lee

Magnolia kobus DC.

Cornus walteri Wangerin

Oenothera glazioviana Micheli in Mart.

Actinodaphne lancifolia (Siebold \& Zucc.) Meisn. in DC.

Lindera erythrocarpa Makino

Weigela subsessilis (Nakai) L. H. Bailey

Morus bombycis Koidz.

Ficus erecta Thunb. var. sieboldii (Miq.) King

Alnus firma Siebold \& Zucc.

Rubus buergeri Miq.

Ulmus parvifolia Jacq.

Viburnum dilatatum Thunb. in Murray

Platycarya strobilacea Siebold \& Zucc.

Cnidium japonicum Miq.

Rhododendron werrichii Maxim.

Prunus serrulata var. quelpaertensis Uyeki

Wisteria floribunda (Willd.) DC.

Broussonetia papyrifera (L.) Lher. ex Vent.

Viburnum furcatum Blume ex Maxim.

Sedum bulbiferum Makino

Eleutherococcus gracilistylus (W. W. Sm.) S. Y. Hu

Viburnum erosum Thunb. in Murray

Equisetum ramosissimum Desf.

Weigela florida (Bunge) A. DC. for. subtricolor Nakai

Toxicodendron trichocarpum (Miq.) Kuntze

Ligustrum lucidum W. T. Aiton

Aster spathulifolius Maxim.

Cornus controversa Hemsl.

Kadsura japonica (L.) Dunal

108.36

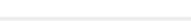

$\begin{array}{lr}79.42 & 87.42 \\ 76.31 & 85.84\end{array}$

$\begin{array}{ll}74.38 & 100.77\end{array}$

$73.50 \quad 110.63$

$\begin{array}{ll}72.08 & 104.36\end{array}$

$71.69 \quad 80.63$

$70.49-105.38$

70.02

$69.69 \quad 99.02$

$69.55 \quad 80.52$

$69.43 \quad 105.09$

$69.08 \quad 79.81$

$68.20 \quad 118.06$

$68.06-88.79$

$67.86 \quad 123.40$

$66.95-103.00$

$66.29 \quad 85.71$

$66.09-84.82$

$66.03 \quad 81.50$

$64.85 \quad 89.00$

$64.39 \quad 91.72$

$64.11 \quad 82.17$

$63.57 \quad 88.80$

$\begin{array}{lr}62.58 & 110.31\end{array}$

$62.30 \quad 91.69$

$62.06 \quad 96.65$

$61.90 \quad 88.10$

$61.74 \quad 97.59$

$61.54 \quad 91.88$

$61.15 \quad 78.44$

$61.09-108.60$

$60.08-137.70$

$56.61 \quad 110.47$

$56.03 \quad 96.52$

$56.00 \quad 92.46$

$55.37 \quad 114.86$

$54.93 \quad 93.72$

54.58

$54.31 \quad 102.81$

54.17

$53.66 \quad 96.03$

53.45

$51.98-113.98$

50.55

$50.09 \quad 109.39$

$49.30 \quad 94.16$

49.11

$48.93 \quad 115.46$

$48.73 \quad 92.97$

$48.70 \quad 100.85$

$48.28 \quad 114.04$

$48.13-2$

125.83

121.97

111.54

91.17

101.82

104.47

89.71

123.65

91.89

80.10

103.48

Zanthoxylum ailanthoides Siebold \& Zucc.

Angelica dahurica (Fisch. ex Hoffm.) Benth. \& Hook. f. ex Franch. \& Sav.

Abbreviations: Entire plants (E), Roots (R), Stems and Twigs (ST), Leaves (L) 
Artemisia japonica Thunb. in Murray

Scutellaria strigillosa Hemsl.

Rhus javanica L.

Machilus japonica Siebold \& Zucc.

Rhus javanica L.

Callicarpa japonica Thunb. in Murray

Abelia mosanensis T. H. Chung

Mallotus japonicus (L. f.) Mull. Arg.

Ginkgo biloba L.

Ficus oxyphylla Miq. ex Zoll.

Staphylea bumalda DC.

Styrax japonicus Siebold \& Zucc.

Staphylea bumalda DC.

Akebia quinata (Thunb.) Decne.

Myrica rubra Siebold \& Zucc.

Eucommia ulmoides Oliv.

Quercus dentata Thunb. in Murray

Euonymus bungeana Maxim.

Diospyros lotus L.

Limonium tetragonum (Thunb.) Bullock

Picrasma quassioides (D. Don) Benn

Tilia taquetii C. K. Schneid.

Prunus maxinowiczii Rupr.

Oenothera stricta Ledeb.

E

45.6

45.61

(n)

L

E

$\mathrm{L}$

44.96

44.82

$44.40 \quad 121.73$

$\begin{array}{ll}43.56 & 94.85\end{array}$

$42.60 \quad 110.03$

$42.36 \quad 89.49$

$42.14 \quad 106.12$

$\begin{array}{ll}41.77 & 98.95\end{array}$

$\begin{array}{lr}41.64 & 104.87\end{array}$

$\begin{array}{ll}41.39 & 91.47\end{array}$

$41.17-117.18$

$40.29-115.05$

$39.70 \quad 82.80$

$38.28+104.33$

$37.89-112.59$

$37.44 \quad 95.14$

$36.06-125.94$

$35.76-104.78$

$34.69 \quad 114.92$

$34.48+104.93$

$33.94 \quad 116.22$

$33.55-112.32$

$33.54 \quad 112.38$

33.27
33.17

Trifolium pratense L.

Illicium anisatum L.

Sapindus mukorossi Gaertn.

Sophora japonica L.

Caesalpinia decapetala (Roth) Alston

Rubus parvifolius $\mathrm{L}$.

Euonymus alatus (Thunb.) Siebold

Camellia japonica L.

Oenothera glazoviana Micheli in Mart.

Veratrum patulum Loes.

Taxillus yadoriki (Siebold ex Maxim.) Danser

Plantago asiatica L.

Callicarpa japonica Thunb. in Murray

Morus alba L.

Sambucus sieboldiana (Miq.) Blume ex Graebn.

Suaeda glauca (Bunge) Bunge

Xylosma congesta (Lour.) Merr.

Euonymus alatus (Thunb.) Siebold

Angelica dahurica (Fisch. ex Hoffm.) Benth. \& Hook. f. ex Franch. \& Sav.

Eleutherococcus gracilistylus (W. W. Sm.) S. Y. Hu

Celtis jessoensis Koidz.

Paederia scandens (Lour.) Merr.

Euphorbia helioscopia L.

Clerodendrum trichotomum Thunb.

Asarum maculatum Nakai

Ampelopsis brevipedunculata (Maxim.) Trautv.

Lamium purpureum $\mathrm{L}$.

Musa basjoo Siebold \& Zucc.

Actinidia polygama (Siebold \& Zucc.) Maxim.

Broussonetia papyrifera (L.) Lher. ex Vent.

Aesculus turbinata Blume

Angelica japonica A. Gray

Salsola komarocii lljin

Cerastium glomeratum Thuill.

$\begin{array}{ll}33.17 & 109.30 \\ 33.14 & 100.98\end{array}$

$33.14-100.98$

$32.52 \quad 124.96$

$32.33-97.99$

$31.66 \quad 106.56$

$31.40 \quad 99.33$

$31.20-118.56$

$31.02 \quad 95.30$

$30.88 \quad 109.28$

$\begin{array}{ll}30.41 & 126.76\end{array}$

30.35

$30.01 \quad 98.02$

$29.83 \quad 98.55$

$29.57+136.28$

$28.73-106.04$

$28.63-122.50$

$28.08-112.45$

$28.06-101.88$

$\begin{array}{ll}27.80 & 90.93\end{array}$

27.40

$\begin{array}{ll}27.17 & 108.00\end{array}$

27.13

$26.93 \quad 123.13$

$26.78-108.73$

$26.67 \quad 104.98$

$26.49+109.88$

$26.48 \quad 99.09$

$26.45-103.76$

$26.28 \quad 102.04$

$26.20-117.06$

25.70

$25.64-99.39$

$25.03 \quad 105.92$

Abbreviations: Entire plants (E), Roots (R), Stems and Twigs (ST), Leaves (L) 
extracts in order to determine the chemical structure of those compounds and to perform more extensive biological evaluations. Many compounds from medicinal plants have been demonstrated as inhibitors of the expression of iNOS in LPS-activated macrophages. Their structures can be categorised as sesquiterpene (Reddy et al., 2006; Choi et al., 2009), flavonoid (Chen et al., 2008; Paoletti et al., 2009), polyacetylenes (Kim et al., 2003), and lignans (Kim et al., 2008). Thus, plants demonstrating inhibitory activities against NO production will be promising candidates for the activity-guided isolation of active components exhibiting iNOS inhibitory activity, which may have therapeutic potential for the treatment of inflammation accompanying overproduction of NO. Further investigations are underway to characterise the active constituents present in these plant extracts.

\section{Acknowledgments}

This research was supported by the Regional Technology Innovation Program (RTI04-02-07), which is managed by the Ministry of Knowledge and Economy, Korea.

\section{REFERENCES}

Chen CC, Tsai PC, Wei BL and Chiou WF. (2008) 8-Prenylkaempferol suppresses inducible nitric oxide synthase expression through interfering with JNK-mediated AP-1 pathway in murine macrophages. Eur J Pharmacol 590: 430-436.

Choi Y, Lee MK, Lim SY, Sung SH and Kim YC. (2009) Inhibition of inducible NO synthase, cyclooxygenase-2 and interleukin-1beta by torilin is mediated by mitogen-activated protein kinases in microglial BV2 cells. Br J Pharmaco/ 156: 933-940

Cragg GM and Newman DJ. (2008) Detection, isolation and structural determination in Bioactive natural products. 2nd ed. CRC press. Boca Raton, F.L. p. 324.

Fan GW, Gao XM, Wang H, Zhu Y, Zhang J, Hu LM, Su YF, Kang LY and Zhang BL. (2009) The anti-inflammatory activities of Tanshinone IA, an active component of TCM, are mediated by estrogen receptor activation and inhibition of iNOS. J Steroid Biochem Mol Biol 113: 275-280.
Henkel T, Machleidt T, Alkalay I, Krönke M, Ben-Neriah Y and Baeuerle PA. (1993) Rapid proteolysis of I kappa B-alpha is necessary for activation of transcription factor NF-kappa B. Nature 365: 182-185.

Hsieh YH, Kuo PM, Chien SC, Shyur LF and Wang SY. (2007) Effects of Chamaecyparis formosensis Matasumura extractives on lipopolysaccharide-induced release of nitric oxide. Phytomedicine 14: 675-680.

Kim BH, Hong SS, Kwon SW, Lee HY, Sung H, Lee IJ, Hwang BY, Song S, Lee CK, Chung D, Ahn B, Nam SY, Han SB and Kim Y. (2008) Diarctigenin, a lignan constituent from Arctium lappa, down-regulated zymosan-induced transcription of inflammatory genes through suppression of DNA binding ability of nuclear factor-kappaB in macrophages. J Pharmacol Exp Ther 327: 393-401.

Kim JH, Park YM, Shin JS, Park SJ, Choi JH, Jung HJ, Park HJ and Lee KT. (2009) Fraxinellone inhibits lipopolysaccharide-induced inducible nitric oxide synthase and cyclooxygenase-2 expression by negatively regulating nuclear factor-kappa B in RAW 264.7 macrophages cells. Biol Pharm Bull 32:1062-1068.

Kim JM, Lee P, Son D, Kim H and Kim SY. (2003) Falcarindiol inhibits nitric oxidemediated neuronal death in lipopolysaccharide-treated organotypic hippocampal cultures. Neuroreport 14: 1941-1944.

Lee TY, Lee KC, Chen SY and Chang HH. (2009) 6-Gingerol inhibits ROS and iNOS through the suppression of PKC-alpha and NF-kappaB pathways in lipopolysaccharide-stimulated mouse macrophages. Biochem Biophys Res Commun 382: 134-139.

MacMicking J, Xie QW and Nathan C. (1997) Nitric oxide and macrophage function. Ann Rev Immunol 15: 323-350.

Moncada S, Palmer RM and Higgs EA. (1991) Nitric oxide: physiology, pathophysiology, and pharmacology. Pharmacol Rev 43: 109-142.

Paoletti T, Fallarini S, Gugliesi F, Minassi A, Appendino G and Lombardi G. (2009) Anti-inflammatory and vascularprotective properties of 8-prenylapigenin. Eur J Pharmaco/ 620: 120-130

Reddy AM, Lee JY, Seo JH, Kim BH, Chung EY, Ryu SY, Kim YS, Lee CK, Min KR and Kim Y. (2006) Artemisolide from Artemisia asiatica: nuclear factor-kappaB (NF-kappaB) inhibitor suppressing prostaglandin $\mathrm{E}_{2}$ and nitric oxide production in macrophages. Arch Pharm Res 29: 591-597.

Oh JH, Kang LL, Ban JO, Kim YH, Kim KH, Han SB and Hong JT. (2009) Anti-inflammatory effect of 4-O-methylhonokiol, a novel compound isolated from Magnolia officinalis through inhibition of NF-kappaB. Chem Biol Interact $\mathbf{1 8 0}$ 506-514

Oh JH, Lee TJ, Park JW and Kwon TK. (2008) Withaferin A inhibits iNOS expression and nitric oxide production by Akt inactivation and down-regulating LPS-induced activity of NF-kappaB in RAW 264.7 cells. Eur J Pharmacol 599: 11-17.

Xie QW, Kashiwabara Y and Nathan C. (1994) Role of transcription factor NFkappa B/Rel in induction of nitric oxide synthase. J Biol Chem 269: 4705-4708. Yoon WJ, Kim SS, Oh TH, Lee NH and Hyun CG. (2009) Abies koreana essential oil inhibits drug-resistant skin pathogen growth and LPS-induced inflammatory effects of murine macrophage. Lipids 44: 471-476.

Zhao F, Wang L and Liu K. (2009) In vitro anti-inflammatory effects of arctigenin, a lignan from Arctium lappa L., through inhibition on iNOS pathway. $J$ Ethnopharmacol 122: 457-462. 